\title{
Isolated chylopericardium due to mediastinal lymphangiomatous hamartoma
}

\author{
R. E. JENNER and HLA OO \\ Departments of Surgery and Pathology, King's College Hospital, London SE5
}

\begin{abstract}
Jenner, R. E. and Oo, H. (1975). Thorax, 30, 113-117. Isolated chlopericardium due to mediastinal lymphangiomatous hamartoma. Isolated chylopericardium is a rare cause of pericardial effusion. Intrapericardial chyle was first noticed by Hasebroek (1888) at necropsy. Twenty years ago Groves and Effler (1954) first reported a clinical case of isolated chylopericardium. The present case is similar to theirs in several respects, and is the nineteenth case to be reported. To our knowledge this is the first British report of an isolated chylopericardium and is the fourth case of isolated chylopericardium due to a mediastinal lymphangiomatous hamartoma to be successfully treated.
\end{abstract}

\section{CASE REPORT}

A 30-year-old housewife was admitted for investigation of an apparent enlargement of the heart in July, 1973. She had been perfectly well until three months prior to admission when she became anorectic and nauseated following a minor fall one week previously. Her symptoms were associated with a full feeling in the epigastrium and these symptoms lasted a week. She then became weak and experienced palpitations and breathlessness on mild exertion. She was investigated by her family doctor for infectious hepatitis as three members of the family had contracted this within the preceding six months. Barium meal and liver function tests were normal, but a chest radiograph showed an enlarged cardiac outline. It was known that in 1967 her chest film was normal. There was no past history of rheumatic fever, tuberculosis or chest trauma, nor had she ever suffered any serious respiratory illness. Her general health was good and she had undergone a normal pregnancy 18 months earlier. She was on no drugs and knew of no allergies.

On examination she appeared a fit woman with no anaemia nor dyspnoea at rest. Physical examination was non-contributory.

investigations The blood picture, blood chemistry, and urinalysis were all normal. ESR $3 \mathrm{~mm} / \mathrm{hr}$. Prothrombin time normal. The Paul Bunnel test was negative. No autoantibodies were detected and LE cells were negative. The chest radiograph showed an apparent enlargement of the heart with normal lung fields (Fig. 1). The electrocardiogram was normal apart from low-voltage complexes. Serum electro-

Green S-McCormack Food Ltd. phoresis was normal. A right heart catheter revealed normal pressures and the right atrial angiogram confirmed a pericardial effusion.

Because she had become asymptomatic and was apyrexial she was discharged home for out-patient follow-up. A presumptive diagnosis of viral pericarditis was made as there was nothing to suggest a bacterial or malignant aetiology. Shortly after discharge the results of viral studies showed a high titre to Coxsackie B virus 1/256 apparently supporting the diagnosis. The effusion, however, did not diminish. It was aspirated one month after discharge and $500 \mathrm{ml}$ of milky fluid was removed. Chemical analysis was as follows: Total lipids $1,840 \mathrm{mg} / 100 \mathrm{ml}$, cholesterol $128 \mathrm{mg} / 100 \mathrm{ml}$, triglyceride content $1,637 \mathrm{mg} / 100 \mathrm{ml}$. The fluid was sterile and the white count $5,000 \mathrm{~mm}^{3}$. Lipoprotein electrophoresis showed that the fluid consisted mainly of chylomicrons. No acid-fast bacilli or cholesterol crystals were seen. This analysis showed that the fluid was chyle and not cholesterol pericarditis. Three days later the patient became acutely distressed and extremely dyspnoeic with tetany. Although the cause of her symptoms was thought to be due to an anxiety state and not tamponade, a further aspiration of $300 \mathrm{ml}$ of chyle by the sub-xyphoid route was performed. The patient was readmitted for surgery.

In September, 1973, a left posterolateral thoracotomy was made through the sixth intercostal space. In order to demonstrate the thoracic duct and any communication between it and the pericardial cavity confectioner's green dye $^{1}$ in a fatty meal was administered five hours preoperatively. Thoracotomy revealed a large lax immobile pericardial sac with dilated lymphatic channels coursing over it. The left lung was free and there were no adhesions over the 


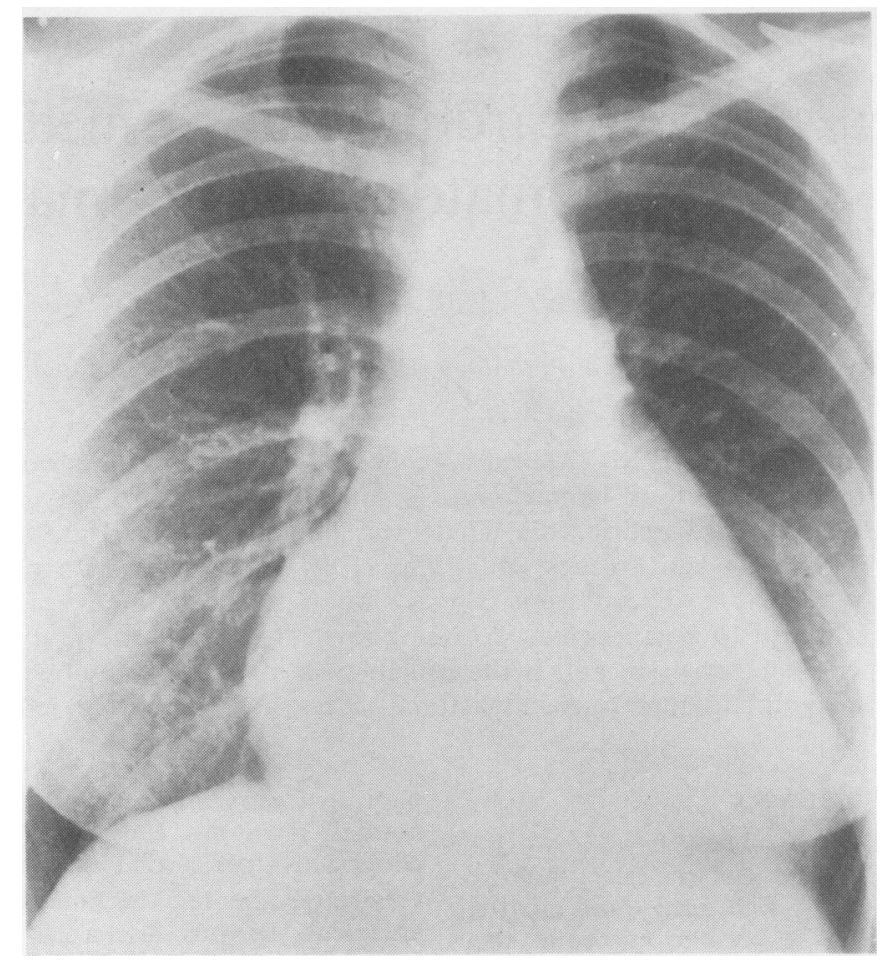

FIG. 1. Chest radiograph taken when the patient was first seen, demonstrating an apparent enlargement of the cardiac silhouette. Note that there is nothing to suggest a mediastinal tumour.

pericardium. Lying above the heart in the anterior mediastinum was a purple-grey sheet of tissue extending to cover the left phrenic nerve.

PROCEDURE The pericardium was opened anterior to the phrenic nerve and $800 \mathrm{ml}$ of unstained milky chyle was aspirated. The heart, epicardial fat, and serous pericardium were normal. Biopsies were taken from the pericardium and the tissue in the anterior superior mediastinum; a frozen section from the latter was reported as benign. The thoracic duct was located in its normal position and found to be thickened but also unstained by the dye. Five millilitres of patent blue dye was injected around the thoracic duct to detect any communication between it and the pericardial cavity. Again no fistulous channels were demonstrated. The thoracic duct was ligated where it entered the posterior mediastinum and an anterior pericardiectomy was performed. The wound was closed in layers after inserting an intercostal pleural drain. This was removed on the third postoperative day having drained only a small quantity of blood. There were no postoperative complications and the patient was discharged home after two weeks. A postoperative lymphangiogram showed that a single thoracic duct had been ligated opposite the eleventh thoracic vertebra (Fig. 2). She was well when she was seen at a six months follow-up clinic, and her chest film showed a normal sized heart. Histology of the excised tissues showed a lymph- $\underset{x}{\mathbb{D}}$ angiomatous hamartoma (Fig. 3) and a slightly thickened pericardium with dilated lymphatics.

\section{DISCUSSION}

Isolated chylopericardium is very rare. More 윽 often it is associated with chyle in the pleural $D$ cavities. Yater (1935), in a review of 100 cases of chylothorax, found three patients who had a $N$ concomitant chylopericardium. The aetiology may be (1) any neoplastic or inflammatory process 0 involving the thoracic duct, (2) trauma by rupture $\mathrm{E}$ or following open-heart surgery, (3) lymphangiectasis (a developmental abnormality in which there is a lymphatic communication be- $\overparen{D}$ tween the thoracic duct and pericardium), and $\stackrel{\mathscr{P}}{+}$ finally, (4) idiopathic. In practice lymphangiectasis and lymphangiomatous hamartomas account for the majority of reported isolated chylopericardiums. Mediastinal lymphangiomas are $\stackrel{\mathbb{Q}}{\varrho}$ extremely rare. Herlitzka and Gale (1958), in a 으 


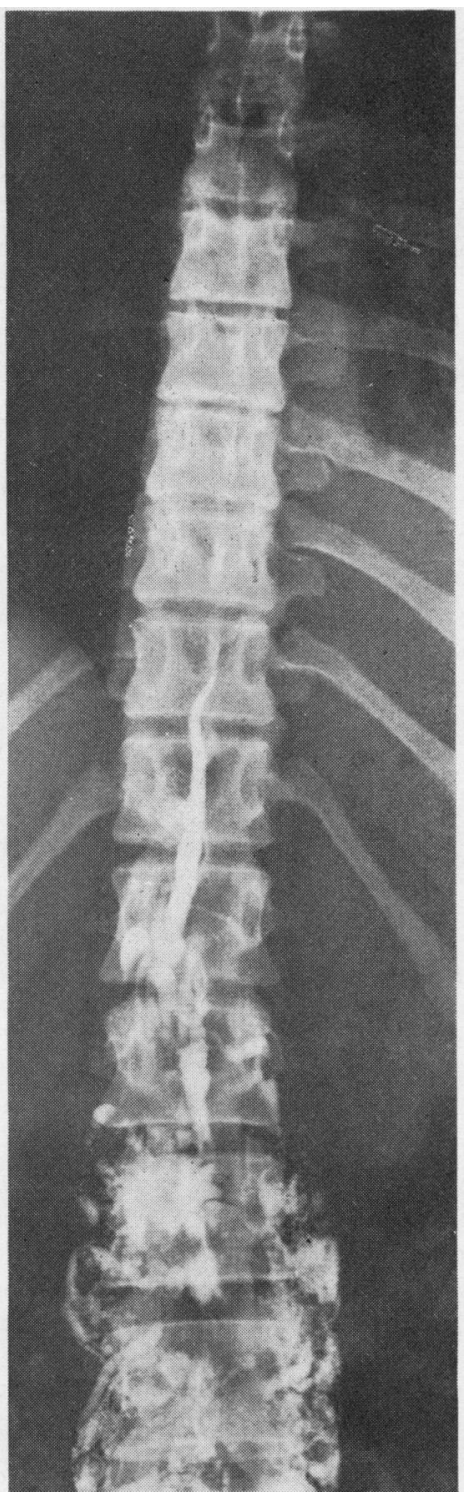

FIG. 2. Postoperative lymphangiogram showing the effects of ligation of the thoracic duct low in the mediastinum.

review of 174 mediastinal tumours and cysts treated surgically, found no case of lymphangioma, and again Nelson, Shefts, and Bowers (1957) encountered only one case of hygroma in a series of 141 mediastinal tumours and cysts. Over 40 cases have now been reported. The most common site for these mediastinal tumours is in the anterior mediastinum, and there is no evidence available to suggest that lymphangiomas may undergo malignant transformation. The prognosis for these tumours is good. The aetiology of lymphangiomas is unknown. They may arise from lymphatic tissue normally present in the area, or they may grow from mesodermal 'rests' which produce imperfect lymphoid channels. All reported cases of chylopericardium due to lymphangiomatous hamartomas have occurred in young people or infants (suggesting a congenital defect), and all in females. A cystic hygroma is a variety of lymphangioma that develops in relation to the lymph sacs of the jugular and iliac regions and possesses considerable growth potential. The tumour in our case had the usual histological characteristics of a lymphangiomatous hamartoma; the only difference between this and a cystic hygroma is in the number and size of the cystic spaces. The effect of chyle in the pericardium is essentially a mechanical one in which the cardiac output is reduced due to diminished filling of the right side of the heart. It is known that chylopericardium may be present for many years before the patient presents. Cardiac tamponade has been noted in about half the reported cases. Although tamponade did not occur in our case, her symptoms were typical. If there is no external loss of chyle, nutritional disturbances and inanition do not follow. In the case reported by Miller, Pruett, and Long (1959) there was dense pleural and mediastinal fibrosis due to the irritant properties of the chyle.

It has always intrigued writers, in isolated chylopericardium, as to why the chyle should collect solely in the pericardial sac. One explanation is that it forms along communications between the pericardium and the thoracic duct. Although these are not described anatomically, it is probable that such communications do arise as a result of faulty embryological development. The anatomy of the thoracic duct has been extensively studied, and several variations are known to exist (Meade, Head, and Moen, 1950). Lymphatics have valves that permit a unidirectional flow into the superior mediastinum. Best and Taylor (1966) found that on ligating the thoracic duct high in the mediastinum of the dog the pressure rose to $15 \mathrm{~cm}$ of water. In our case it is possible that chyle refluxed from the thoracic duct into the pericardial sac along dilated channels. Alternatively, the chyle could have flowed into the pericardial sac from the tumour into which the thoracic duct flowed. It is more difficult to account for those cases where there is no tumour or obstruction. Bartel and Neute (1964) suggested 


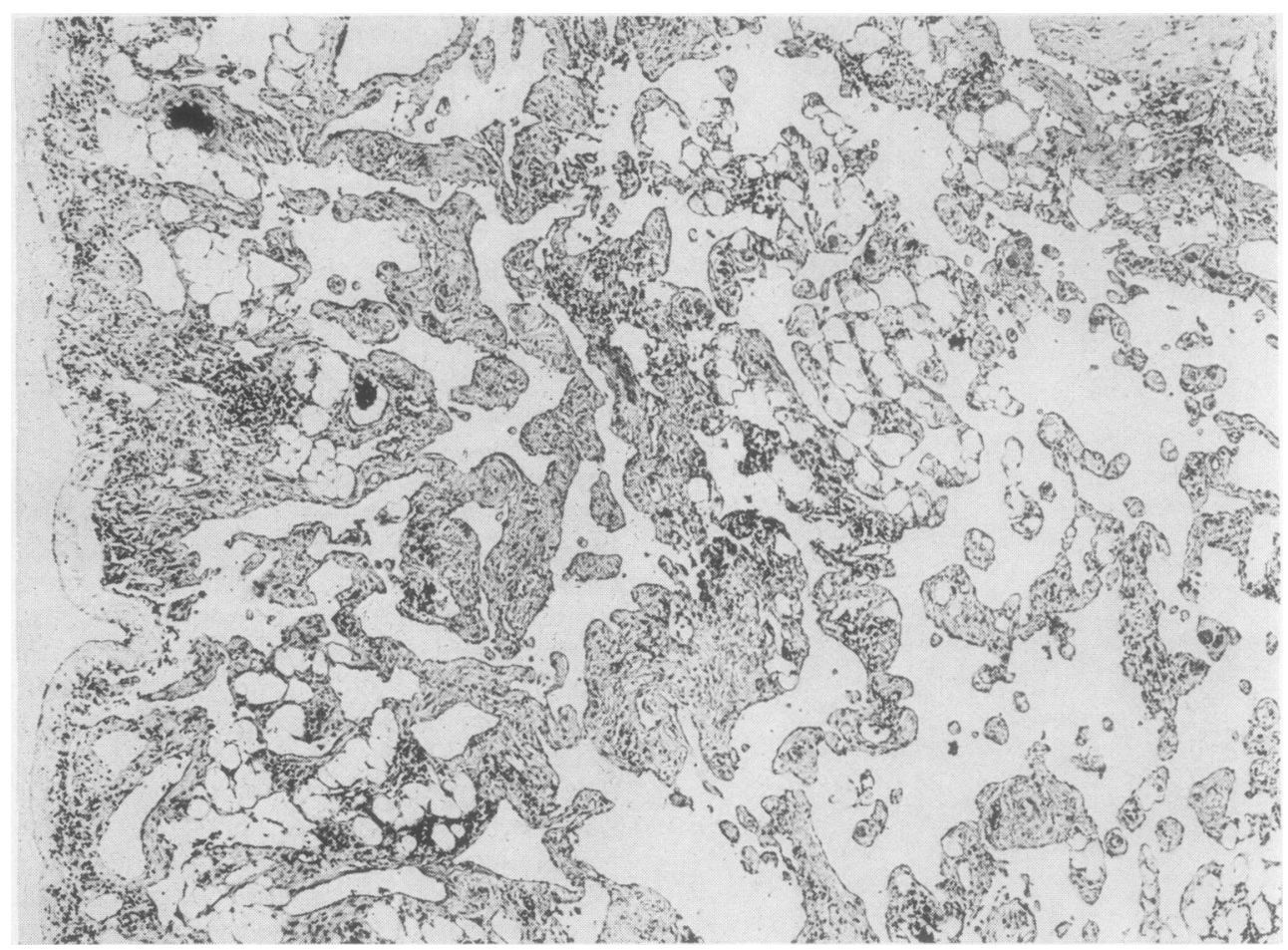

FIG. 3. A typical section of the tumour showing numerous irregular cystic spaces of varying sizes lined by a layer of flattened endothelial cells. Focal lymphoid aggregates are present in the intervening fibrocollagenous walls $(H$ and $E \times 45)$.

that such cases may be due to an abnormal permeability of the lymphatics. Although it would seem that obstruction of the thoracic duct would be the common factor in chylopericardium, many cases of thoracic duct obstruction are unassociated with the accumulation of chyle, and it is known that the thoracic duct can be ligated in the superior mediastinum without causing chylopericardium. Blalock, Cunningham, and Robinson (1936) produced chylopericardium and chylothorax experimentally in dogs by ligating the superior vena cava above the azygos vein, but not if the thoracic duct had been ligated at a previous thoracotomy. These authors were unable to produce chylopericardium in dogs by tying the main right and left lymphatic ducts, indicating that there are a number of other lymphatics which empty into the superior vena cava or its branches.

The pathology may be missed because it is difficult to obtain a good examination of the whole pericardium from a standard right or left thoracotomy. The patient of Groves and Effler (1954) illustrates this and also another important operative detail. In their first operation through a left thoracotomy the lax and distended pericardium was simply drained and a $4 \mathrm{~cm}$ window was made to create a fistula into the left hemithorax. Three months later the massive pericardial effusion had recurred. A right thoracotomy was then performed which revealed a lymphangiomatous hamartoma which was not evident before. A large portion of this tumour was excised and more importantly the thoracic duct was ligated low in the chest.

Once milky fluid has been aspirated from the pericardium the diagnosis of chylopericardium should be easy. The only differential diagnosis to $\mathrm{C}$ consider is cholesterol pericarditis. Cholesterol $\underset{2}{2}$ pericarditis has been associated with hypertension, tuberculosis, carcinoma, mitral stenosis, atrial septal defect, and arthritis (Brawley, Vasko, and Morrow, 1966). Apart from cardiac catheterization or diagnostic ultrasound, further preoperative investigations should include a lymphangiogram, although this may not be helpful in a positive way, as in the case reports by Hudspeth and 
Miller (1966) and Puig-Massana, Murtra, and Calbet (1972). Both their cases had normal preoperative lymphangiograms, although it was clear there must have been an abnormal communication between the thoracic duct and the pericardium. Definite proof that such a communication exists can be shown by giving the patient a lipophilic dye in fat, for example, Sudan III in corn oil, and recovering the dye later by pericardial aspiration and ether extraction. More simply, an isotopically labelled fat ${ }^{131}$ I-labelled triolein) can be given orally followed by a cardiac scan. Both these tests have been shown to be reliable. In our case a mixture of green $S$ dye and butter administered preoperatively failed to demonstrate the thoracic lymphatic system. Peroperative demonstration of fistulous lymphatic tracts is best performed by injection of dye directly into the thoracic duct if this is possible.

The surgical objectives in this condition are to relieve the raised intrapericardial pressure and prevent recurrent accumulation of chyle, and also to search for a possible cause for the condition. Uniformly good results have come from pericardial fenestration and ligation of the thoracic duct low in the mediastinum. Besides permitting decompression, pericardial fenestration should also prevent the possible late onset of constrictive pericarditis. However, of the two procedures, ligation of the thoracic duct would appear to be the most important. The only two postoperative deaths reported have occurred when the thoracic duct was not ligated.

We thank Mr. A. M. Macarthur and Dr. D. A. Chamberlain for their permission and help in reporting this case.

\section{REFERENCES}

Bartel, J. and Neute, E. (1964). Das isolierte chyloperikard. Cardiologia, 45, 251 .
Best, C. H. and Taylor, N. B. (1966). The physiological basis of medical practices. In $A$ Text in Applied Physiology, 8th edition, p. 508. Williams and Wilkins, Baltimore.

Blalock, A., Cunningham, R. S., and Robinson, C. S. (1936). Experimental production of chylothorax by occlusion of the superior vena cava. Annals of Surgery, 104, 359.

Brawley, R. K., Vasko, J. S., and Morrow, A. G. (1966). Cholesterol pericarditis. American Journal of Medicine, 41, 235.

Groves, L. K. and Effler, D. B. (1954). Primary chylopericardium. New England Journal of Medicine, 250, 520.

Hasebroek, G. (1888). Analyse einer chylösen pericardialen Flüssigkeit (chylopericardium). Zeitschrift fur Physiologische Chemie, 12, 289.

Herlitzka, A. and Gale, J. W. (1958). Tumors and cysts of mediastinum; survey of 174 mediastinal tumors treated surgically during past 18 years at the University of Wisconsin Hospitals. Archives of Surgery, 76, 697.

Hudspeth, A. S. and Miller, H. S. (1966). Isolated (primary) chylopericardium. Journal of Thoracic and Cardiovascular Surgery, 51, 528.

Meade, R. H. Jr., Head, J. R., and Moen, C. W. (1950). The management of chylothorax. Journal of Thoracic Surgery, 19, 709.

Miller, S. U., Pruett, H. J., and Long, A. (1959). Fatal chylopericardium caused by hamartomatous lymphangiomatosis. American Journal of Medicine, 26, 951 .

Nelson, T. G., Shefts, L. M., and Bowers, W. F. (1957). Mediastinal tumors; analysis of 141 cases. Diseases of the Chest, 32, 123.

Puig-Massana, M., Murtra, M., and Calbet, J. M. (1972). Idiopathic massive chylopericardium. British Heart Journal, 34, 431.

Yater, W. M. (1935). Non-traumatic chylothorax and chylopericardium; review and report of a case due to carcinomatous thromboangiitis obliterans of the thoracic duct and upper great veins. Annals of Internal Medicine, 9, 600.

Requests for reprints to: R. E. Jenner, FRCS, Department of Surgery, King's College Hospital, Denmark Hill, London SE5. 